International Research Journal of Engineering, IT \& Scientific Research
Available online at https://sloap.org/journals/index.php/irjeis/
Vol. 5 No. 5, September 2019, pages: 1 7
ISSN: 2454-2261
https://doi.org/10.21744/irjeis.v5n5.720

\title{
Brain and Learning on Adolescence Stage
}

\author{
Brenda Stefania Guale Vasquez ${ }^{\text {a }}$ \\ Carlos Julio Bastidas Martinez ${ }^{\text {b }}$ \\ María Elena Moya Martinez ${ }^{\mathrm{c}}$ \\ María Angelica Indacochea Vasquez ${ }^{d}$
}

Article history:

Received: 09 January 2019

Accepted: 31 July 2019

Published: 28 August 2019

\section{Keywords: \\ adolescence; \\ brain; \\ conceptualization; \\ learning; \\ teaching;}

\begin{abstract}
Research shows adolescent learning by analyzing brain development at the age of 10 to 19 years. A literature review method has used in the investigation from 1997 to 2019 with the aim of demonstrating the incidence of the brain in the teaching system. An analysis of the conceptualization of adolescence, brain, learning, behavior has shown; where several authors who have studied the subject have analyzed. In addition, the behavior of people influences the teaching process, for this reason, shows the psychosocial characteristics of the adolescent that give rise to the design and predisposition of the use of innovative methodologies to teach classes in educational institutions. The study of the brain and learning, adolescence, generalities and psychosocial characteristics of the adolescent will help in the intervention and prevention of future social problems that many teenagers are currently affected. Understanding a teenager is complex; but if you can know what you like, what you want, this will serve to be able to interact with your same ideals and reach meaningful and valid teaching.
\end{abstract}

2454-2261 ${ }^{\odot}$ Copyright 2019. The Author. This is an open-access article under the CC BY-SA license (https://creativecommons.org/licenses/by-sa/4.0/) All rights reserved.

\section{Author correspondence: \\ Brenda Stefania Guale Vasquez, \\ Masters student, Pontificia Universidad Católica del Ecuador, Portoviejo, Manabí, Ecuador. \\ Email address: brenda.guale@educacion.gob.ec}

\section{Introduction}

It is necessary to know the development of the brain in the teaching-learning process since emotional and behavioral changes are experienced in adolescence, causing teacher and student great difficulties in class development. In addition, some mental disorders appear, which are notable due to the hormonal change of melatonin.

a Pontificia Universidad Católica del Ecuador, Portoviejo, Ecuador

${ }^{\mathrm{b}}$ Pontificia Universidad Católica del Ecuador, Portoviejo, Ecuador

${ }^{\mathrm{c}}$ Pontificia Universidad Católica del Ecuador, Portoviejo, Ecuador

${ }^{\mathrm{d}}$ Pontificia Universidad Católica del Ecuador, Portoviejo, Ecuador 
In the adolescence stage, students are ready to experience new challenges, characterized by somatic growth and development, and the onset of pubertal changes and sexual characteristics. Also in decision making in both the family, sentimental and professional environment. Therefore adolescence is an age of transition; Therefore, bad teaching can cause damage that would have an impact on society such as intra-family problems, vandalism, drug addiction, prostitution, homosexuality.

The adolescent proposes rules and rules of his own and due to the development and maturation of the brain; until reaching adulthood, significant changes in their behavior and academic performance will arise and this makes it necessary to carry out an analysis to place it in the teaching and coexistence process within the classroom and this will serve teachers as a guide to understand the way of learning of the teenager.

\section{Materials and Methods}

The methods that governed this research were the hypothetical-deductive that allowed to verify the analysis of the concepts investigated related to the ways of learning of adolescents, to show the importance of the assessment within the classrooms since many teachers are unaware of the theme and the influence it has on learning. In addition to a broad search in relation to the topic of research trends; adolescence and learning, brain and learning

\section{Results and Discussions}

\subsection{The Brain and Adolescence}

The human brain is a biological and social organ responsible for the functions and processes related to thinking, intuition, imagination, playfulness, action, writing, emotion, consciousness; It also responds to changes in the environment. It can modify the connections between neurons, the network of capillaries that provide them with oxygen and nutrients and produce new neurons, all during the life of the person and not only in adolescence or the first years of adulthood as previously believed (Velásquez et al., 2009; Mahendra, 2016; Mendoza et al., 2019)).

It is understood that the complexity of the human brain reveals the need to obtain and learn new knowledge; Every teenager has several ways of learning; reacts to situations and circumstances through stimuli, creates and seeks new forms of communication between the control centers of specific and associated processes, depending largely on age.

On the other hand, experts in neurosciences were of the opinion that almost half of the brain connections were already established in childhood, and that the only development task that remained was to ensure those connections (UNICEF, 2019) but on the contrary even the brain In the adolescent he continues to produce hormones, which determines that the student must be guided by his knowledge that he has acquired until this stage.

Recent studies show that the brain experiences a continuous cycle of growth every year and that after approximately 11 years of age, an explosion of electrical and physiological activity occurs, which dramatically reorganizes billions of neural networks that affect the emotional skills and physical and mental skills. Also at the beginning of adolescence the maturation of the brain and the reorganization of neurons also begins and it is logical to understand since there are many adolescents committed to some type of learning and development of one of the intelligence; the teaching process cannot be altered although it is true that children from the age of five are very skilled in learning; the learnings must be respected and respected according to the stages of life.

The analysis of this result showed that the development and maturity of the brain influence the learning of adolescents. And according to author Velásquez and UNICEF, the brain modifies the connections between neurons and their production; indicating that this process occurs throughout life and that in adolescents it is important to consolidate knowledge.

\subsection{Generalities of Adolescence}

The stage of adolescence is between early childhood and adulthood; adolescents go through pure changes and biological, psychological and social transformations and it is also characterized by the generation of conflicts, confusions, doubts; Some are causes of generating social problems. However, it is not only a period of adaptation to bodily changes but a phase of great determinations towards greater psychological and social independence. 
According to the concepts conventionally accepted by the World Health Organization, adolescence is the stage that runs between 10 and 19 years, considering two phases; early adolescence 10 to 14 years and late adolescence 15 to 19 years (Perez \& Santiago, 2019; Herianto, 2017; Suarez et al., 2019)). Adolescence is one of the most extraordinary and at the same time more complex stages of life, in this age every teenager acquires responsibility and accepts changes in his personality leaves childhood and enters the world of decision making in the same sense that he acquires new knowledge and possibly change cultures and beliefs; because this is the age of moral issues. It will no longer depend on the parents' responses. Now they will look for their own answers, which is why it is necessary that they receive a correct education and that their learning is meaningful.

In this part of the result its could identify that there are different ages to refer to adolescence; Perez and Santiago were cited in this case, referring to WHO World Health Organization indicated that adolescence is between the ages of 10 and 19, thus giving subdivisions that can be related to the socio-educational environment of student development, such form that shows two phases of adolescence: an early one. Likewise, it was concluded that adolescents due to their pubertal development have their own and unique behavior of each person, differentiating themselves in their way of thinking, speaking, dressing, walking, and relating to the rest of their environment.

\subsection{Erik Erikson's Psychosocial Theory}

The human being goes through a sequence of cycles from birth to adulthood, it is necessary to describe the fifth stage called adolescence and puberty; Erikson concluded in his theory that adolescents demonstrate security of what they want in life and their ability to learn; In the same way, he added that he is immersed in the failure to know what he wants, he cannot decide whether to study or not to study, or how to present himself before the situations or factors of coexistence: due to his confusion and his abrupt changes in moods.

Therefore it can be synthesized that this division of human development known as identity against confusion of roles is the predominant one; since adolescents develop a strong sense of themselves or are equally confused about their identity and the role they play in life (Salinas, 1997; Gani et al., 2018; Alava \& Martinez, 2019)).

Before the insecurity of teenagers; the information they acquire will become irrelevant at times; Thus, in a classroom, a minority group of students is not interested in what the teacher explains or teaches, they only attend to approve the school year.

In the analysis of this result it was found that the theory of psychologist Erik Erikson quoted by Salinas, indicated that every person goes through behavioral transitions, that in adolescence is the most worrisome because at this stage insecurity is shown, doubts, fears, conflicts, and that teachers must intervene to ensure a meaningful education along the way of this process.

\subsection{Psychosocial Characteristics of Adolescents}

It is very common to find a clear and determined young man in which he wishes to do but there is also a group without knowing what to do what to decide to study and even the confusion of sexual gender; as well; This stage is very complex and according to Pineda \& Aliño (2019), that indicated the following: psychosocial aspects are integrated into a series of characteristics and behaviors that are present to a greater or lesser extent during the adolescence stage; and these are: the search for themselves and their identity, the need for independence and at the same time the formation of groups, a constant evolution of concrete and abstract thinking, intellectual needs and the ability to use knowledge reach their maximum efficiency; At this point it is necessary to emphasize the interest that a teenager shows superiority before their peers. In addition to this the confusion and contradictions of identity, manifesting changes in sexual behaviors and moods; and this at the same time generates conflicts with their parents.

In this period the students become more analytical, begin to form their own language and their symbology to find their own answers and reach their conclusions by developing a scale of values in correspondence with their image of the world; To answer their unknowns of the life project that they raise they choose an occupation and make the decision of being in their professional life.

Analyzed the psychosocial characteristics in adolescence, it was found that identity and personal independence develop at this age; In addition, the change of the physical and behavioral from children to adolescents directly affects the brain since these are caused biologically, such as, for example, the sexual organs, for this reason, the adolescent cannot go unnoticed; This stage can be very rigorous of personal care, body beautification or it can be catastrophic. Some adolescents who do not run with the luck of not suffering from acne although they are biological

Vasquez, B. S. G., Martinez, C. J. B., Martinez, M. E. M., \& Vasquez, M. A. I. (2019). Brain and learning on adolescence stage. International Research Journal of Engineering, IT \& Scientific Research, 5(5), 1-7. https://doi.org/10.21744/irjeis.v5n5.720 
terms that should not be detailed in this research it is important to emphasize that for a teenager to learn he must feel good.

In this analysis, it was verified that the psychosocial characteristics are fixedly defined in two groups of adolescents: the first conscious and determined group is their behavioral, social, sentimental and sexual decisions, and the second unconscious and doubtful group of their ideas thoughts, feelings.

\subsection{Theories of Learning in Adolescence}

Theories of learning describe the processes by which human beings learn. Numerous psychologists and pedagogues have contributed broad theories in the field. Likewise Schunk (1997), provides that No definition of learning is accepted by all research theorists and education professionals, and those that exist are numerous and varied, since there are disagreements about the precise nature of learning and it also indicates that it is the change behavioral or change in the ability to behave; being thus main characteristic of the man since he is always on the search and the verification of something.

We use "learning" terms when someone becomes capable of doing something other than what they did before. Therefore the numerous theories help to understand, indicate and control human behavior, in turn developing learning strategies and trying to explain how subjects access knowledge and this also uses necessary behavioral strategies; It is also required the change or development of new actions or modifications of the present ones there is an approach of the learned or cognitive to differentiate a new learning.

According to the analysis performed, the different theories or forms of learning were checked; emphasizing that teachers must apply strategies and innovations when teaching their classes to attract the student. Since the teenager is easily distracted and at the same time is going through psychosocial changes that are more important in his daily life.

\subsection{Teen Learning}

No doubt every teenager is different; He has different perceptions, different tastes and of course his knowledge will be acquired differently, for this each teacher must use innovative methodologies in their teaching; because teaching does not symbolize imposing, on the contrary, it should be suggested, indicate different forms and options of studies so that each student values learning and is interested in applying in their social environment (Bombino, 2019). In addition, adolescence is the stage indicated to reform the teaching of values and teachers, are responsible for directing the process of formation and modification of them. Directed teaching in values; a necessary and indispensable task for society; and with the contribution of educational institutions the human sense towards the environment will be forged in the new generations; and this can be achieved from a classroom.

Teen learning is paramount because it reinforces the scientific, human and social knowledge acquired during childhood; this stage should be used because at the same time the brain reaches its development and total maturity, therefore it is necessary to seal these contents with a good teaching process.

It was verified after the analysis of this result; that the adolescent's teaching should focus on knowing the functions of the student's brain and understanding the adolescent's behavior to improve academic performance in class.

\section{Conclusion}

At present, several educational scientists and neurologists can be named showing and affirming several learning theories and methodologies, but this is not the only thing we should know; because the human brain is infinite in the way of learning although there are data or percentages of intellectual coefficients man always exceeds the figures, there is no same methodology to teach; Teaching differs in a teenager because he is in a state of transition and for that reason he would need the application of the various methodologies to see which one is accepted by the student. All are necessary but only one is from which they would learn.

The conclusion of this research it is important to emphasize that there are two complex terms and very difficult to embrace in a single brain and adolescent investigation and the combination together with learning becomes interesting and important I can indicate that the best ways for a young person to learn is that Your teacher understands your thoughts, feelings, attitudes, behaviors, social relationships, and after having accepted your way and lifestyle you can find a way to teach and apply the methodology that the adolescent needs; a teenager who is in 
the process of change also his learning must transitory must include current, practical and truthful content, the student should not be confused.

Conflict of interest statement and funding sources

The authors declared that they have no competing interest.

Statement of authorship

The authors have a responsibility for the conception and design of the study. The author(s) have approved the final article.

\section{Acknowledgments}

Special recognition is made to the group of researchers who practically conducted this research. To Mr. Jhonny Lino, for the support given in my improvement, motivating me daily in the process of achieving the goal.

Vasquez, B. S. G., Martinez, C. J. B., Martinez, M. E. M., \& Vasquez, M. A. I. (2019). Brain and learning on adolescence stage. International Research Journal of Engineering, IT \& Scientific Research, 5(5), 1-7. https://doi.org/10.21744/irjeis.v5n5.720 


\section{References}

Alava, E. E., \& Martinez, M. E. M. (2019). Impact of teaching-learning process for brain. International Journal of Health Sciences, 3(1), 33-40. https://doi.org/10.29332/ijhs.v3n1.304

Bombino, LL, \& Reinoso Porra, E. (2019). The education in values of the new generations in the school context. Atlante Notebooks of Education and Development, (July).

Burgos, BMV, de Cleves, NR, \& Márquez, MGC (2009). The brain you learn. Rasa tab, (11), 329-347.

Gani, A. A., Ibrahim, N., \& Khaerudin, -. (2018). Multimedia use and learning styles on learning achievement in social studies. International Journal of Social Sciences and Humanities, 2(2), 187-193. https://doi.org/10.29332/ijssh.v2n2.163

Herianto, E. (2017). The effect of learning strategy, achievement motivation, and communication skill toward learning outcomes on the course PMPIPS-SD at PGSD. International Research Journal of Management, IT and Social Sciences, 4(5), 1-11.

Mahendra, I. W. E. (2016). Contextual learning approach and performance assessment in mathematics learning. International Research Journal of Management, IT and Social Sciences, 3(3), 7-15.

Mendoza, L. R. M., Martinez, M. E. M., \& Suarez, A. M. S. (2019). The brain as a fundamental axis in learning process. International Research Journal of Engineering, IT \& Scientific Research,5(4), 38-45. https://doi.org/10.21744/irjeis.v5n4.689

Perez, S. P., \& Santiago, M. A. (2019). Adolescence is one of the phases of life. Adolescence is one of the phases of life, 16.

Pineda, S., \& Aliño, M. (2019). Manual of clinical practices for the attention of adolescence. 17. Obtained from Manual of clinical practices for the attention of adolescence: http://www.sld.cu/galerias/pdf/sitios/prevemi/capitulo_i_el_concepto_de_adolescencia.pdf

Salinas, C., Fránquiz, M. E., \& Reidel, M. (2008). Teaching world geography to late-arrival immigrant students: Highlighting practice and content. The social studies, 99(2), 71-76. https://doi.org/10.3200/TSSS.99.2.71-76

Schunk, DH (1997). Learning theories . Pearson education.

Suarez, A. M. S., Martinez, M. E. M., \& Mendoza, L. R. M. (2019). Brain and learning. International Journal of Social Sciences and Humanities, 3(2), 128-135. https://doi.org/10.29332/ijssh.v3n2.302

UNICEF (2019). Obtained from adolescence a fundamental stage: https://www.unicef.org/ecuador/pub_adolescence_sp.pdf 


\section{Biography of Authors}

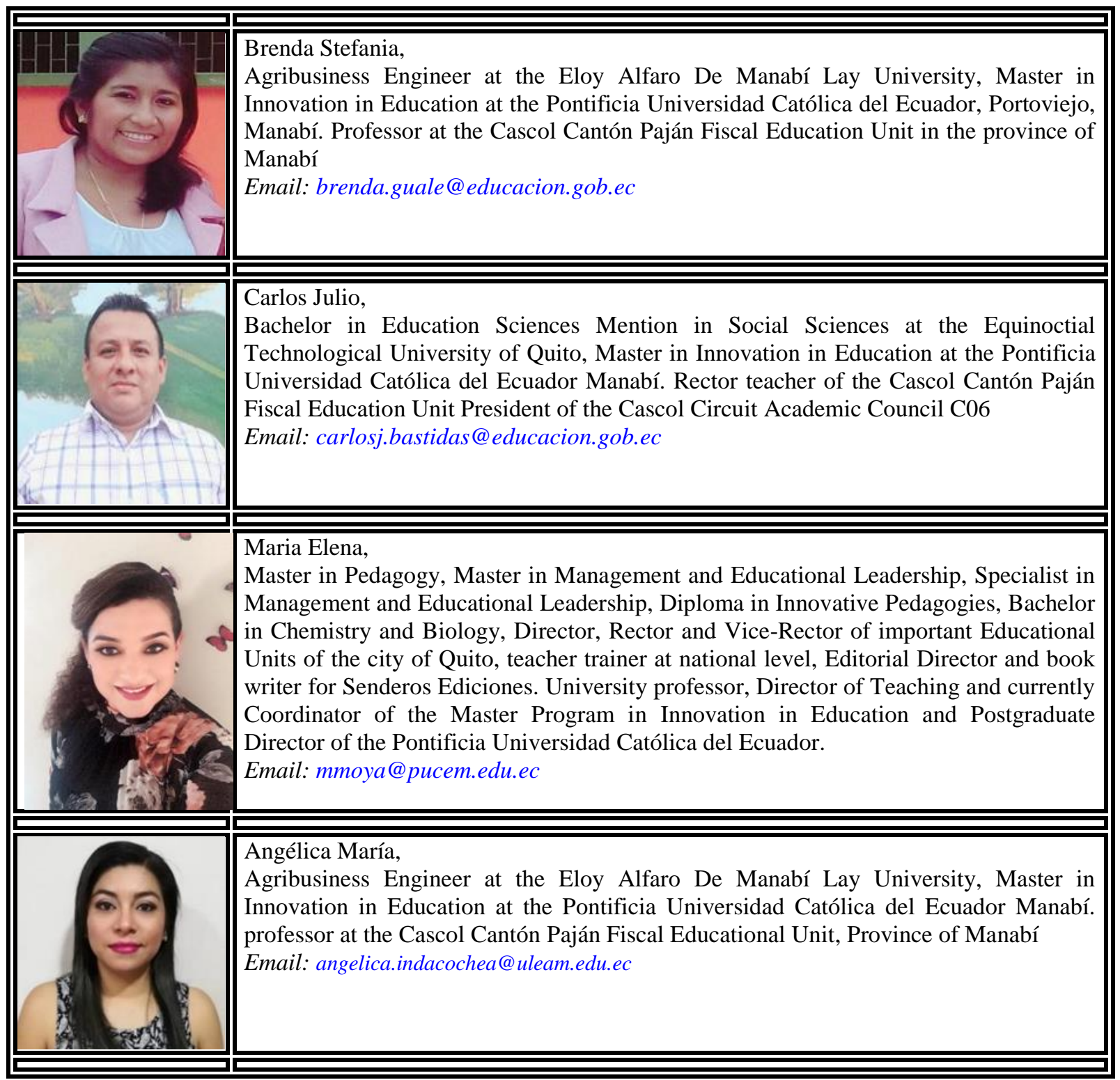

Vasquez, B. S. G., Martinez, C. J. B., Martinez, M. E. M., \& Vasquez, M. A. I. (2019). Brain and learning on adolescence stage. International Research Journal of Engineering, IT \& Scientific Research, 5(5), 1-7. https://doi.org/10.21744/irjeis.v5n5.720 